\title{
The human cathelicidin antimicrobial peptide LL-37 as a potential treatment for polymicrobial infected wounds
}

\author{
Allen J. Duplantier ${ }^{1}$ and Monique L. van Hoek ${ }^{1,2}$ * \\ ${ }^{1}$ National Center for Biodefense and Infectious Diseases, George Mason University, Manassas, VA, USA \\ ${ }^{2}$ School of Systems Biology, George Mason University, Manassas, VA, USA
}

\author{
Edited by: \\ Peter F. Zipfel, Leibniz Institute for \\ Natural Product Research and \\ Infection Biology, Germany \\ Reviewed by: \\ Jan Peters, University of Tennessee \\ Health Science Center, USA \\ Kristian Riesbeck, Lund University, \\ Sweden \\ *Correspondence: \\ Monique L. van Hoek, National \\ Center for Biodefense and Infectious \\ Diseases, George Mason University, \\ Discovery Hall, MS 1H8, 10910 \\ University Blvd, Manassas, VA 20110, \\ USA \\ e-mail: mvanhoek@gmu.edu
}

\begin{abstract}
Diabetic patients often have ulcers on their lower-limbs that are infected by multiple biofilmforming genera of bacteria, and the elimination of the biofilm has proven highly successful in resolving such wounds in patients. To that end, antimicrobial peptides have shown potential as a new anti-biofilm approach. The single human cathelicidin peptide LL-37 has been shown to have antimicrobial and anti-biofilm activity against multiple Gram-positive and Gramnegative human pathogens, and have wound-healing effects on the host. The combination of the anti-biofilm effect and wound-healing properties of LL-37 may make it highly effective in resolving polymicrobially infected wounds when topically applied. Such a peptide or its derivatives could be a platform from which to develop new therapeutic strategies to treat biofilm-mediated infections of wounds. This review summarizes known mechanisms that regulate the endogenous levels of $L L-37$ and discusses the anti-biofilm, antibacterial, and immunological effects of deficient vs. excessive concentrations of LL-37 within the wound environment. Here, we review recent advances in understanding the therapeutic potential of this peptide and other clinically advanced peptides as a potential topical treatment for polymicrobial infected wounds.
\end{abstract}

Keywords: antimicrobial peptide, chronic wounds, biofilm, infected wounds, cathelicidin

\section{INTRODUCTION}

The goal of this review article is to explore and analyze in-depth the recent published literature and ongoing clinical trials that have focused on the potential of the antimicrobial peptide (AMP) LL37 to be used in infected wound treatment, especially as a potential topical treatment. We are especially concerned with the treatment of wounds that may contain multiple, biofilm-forming organisms (polymicrobial infections). Many significant technical and clinical advances have been made in this area, and we saw a need for an overview of the current state of the art. In addition, we sought to link the effects of LL-37 on the pathogen with its concomitant effects on the host in the infected wound model system, as this potentially may be a synergistic activity that illustrates the benefits of LL-37 (or derivatives) as a potential therapeutic agent for the topical treatment of infected wounds. Finally, we sought to identify some of the remaining challenges that exist in bringing such a treatment to patients.

Bacterial biofilms inhibit wound healing and promote infection. Opportunistic pathogens, such as Pseudomonas aeruginosa and Staphylococcus aureus are able to infect open wounds such as chronic diabetic foot ulcers (Johnson et al., 2007; James et al., 2008; Murray, 2008a,b; Ressner et al., 2008; Wolcott et al., 2008, 2010a; Brown et al., 2010; Fisher et al., 2010). These organisms have a prodigious ability to produce biofilm that makes eliminating them from wounds extremely challenging. The immune system can be ineffective against the infections as a result of poor circulation particularly in diabetic patients. Antibiotics can be ineffective due to lack of penetration through the biofilm or due to colonization by resistant strains and poor circulatory delivery of systemic antibiotics. The result can be chronically infected wounds with polymicrobial bacterial populations that threaten the lives and limbs of patients (Lopez-Leban et al., 2010). The current approach to controlling these severe infections in diabetic patients includes performing 70,000 lower-limb amputations every year in the USA (Figure 1) (Wolcott et al., 2010a). With 26 million (and rising) diabetics in the US, these life-threatening infections are likely to increase. There are few new antibiotics in the drug-development pipeline that are effective against Pseudomonas and Staphylococcus within these wounds. A combination approach of wound-care management (debridement), systemic antibiotics, plus the use of topical anti-biofilm agents (e.g., xylitol) has been shown to reduce the ability of the biofilm to persist (Wolcott and Rhoads, 2008; Lopez-Leban et al., 2010; Wolcott et al., 2010a,b,c) and has been shown to be one effective approach to healing these wounds. Once the biofilm collapses, the infecting bacteria are unprotected and then cleared by the immune system and antibiotics. AMPs are a potential new topical therapeutic agent to include in this combinatorial approach particularly due to their anti-biofilm activity at low concentrations. Humans make a single cathelicidin AMP, LL37, which has both antimicrobial and anti-biofilm properties and can eradicate preformed biofilms in vitro (Overhage et al., 2008; Dean et al., 2011a,b). Thus, there is great interest of LL-37 as a potential therapeutic for polymicrobial infected wounds. In this review, we will survey recent research on the host and pathogen targets of this peptide, and its potential for use in the treatment of polymicrobial infected wounds. 


\section{Number of Diabetics (US) and Lower-Limb amputations.}

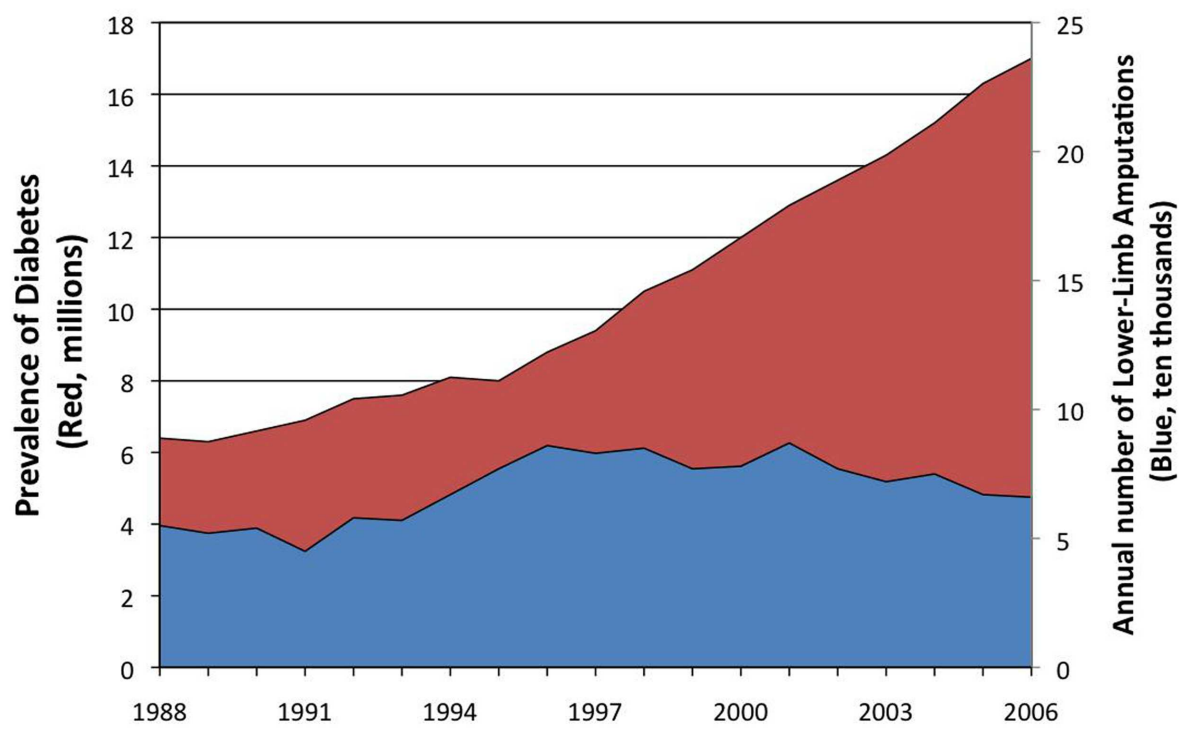

FIGURE 1 | Prevalence of diabetes in the US (red) and the number of lower-limb amputations. Between 15 and $25 \%$ of diabetics will develop diabetic foot ulcers in their lifetime. Diabetics often suffer from severe, chronic infections of those ulcers (James et al., 2008; Wolcott et al., 2008, 2010a; Fisher et al., 2010) leading to as many as 70,000 lower-limb amputations per year in the United States (Wolcott et al., 2010a). These biofilm-associated infections and their sequelae greatly contribute to the healthcare cost for diabetic patients; as much as $\$ 174$ billion is spent annually on diabetes in the United States (Mikkelsen et al., 2011). With almost 26 million diabetics (8.3\% of the population) in the US currently and the number expected to rise, the number of these life-threatening infections is likely to increase.

\section{BIOFILMS IN WOUNDS}

Bacteria prevailingly exist within biofilms - sessile communities of microorganisms that synthesize and surround themselves with a slimy, hydrated polymeric matrix attached to a solid surface. Biofilm-forming bacteria (while in the planktonic state) go through an initial "twitching" stage where they explore a surface prior to attachment in a Type IV-pili dependent manner. Once irreversibly attached, the bacteria begin to grow, differentiate and excrete a hydrated polymeric matrix within which a micro-colony of bacteria is formed (Figure 2). The micro-colony then uses quorum-sensing molecules to communicate from cell to cell. While embedded in this matrix, bacteria exhibit an altered phenotype with respect to growth rate and gene transcription (Costerton et al., 1995; Wolcott et al., 2010b). The transition of planktonic bacteria from a free-swimming mode (using flagella in the case of Pseudomonas) to the formation of (and growth within) a biofilm environment attached to a surface is described in Figure 2 and has been well reviewed (Monds and O'Toole, 2009; Abee et al., 2011; Mikkelsen et al., 2011; Petrova and Sauer, 2012). Once within a biofilm, bacteria can thrive as they are protected from the immune system, nutrient deprivation, changes in $\mathrm{pH}$, and antimicrobial agents (Monds and O'Toole, 2009). Growth within the biofilm eventually reaches its maximum and is followed by dispersion of the bacteria from the mature biofilm, believed to be induced, in part, by short-chain fatty acid signaling molecules such as cis-2-decenoic acid (Davies and Marques, 2009).

Chronic infected wounds may result from pressure sores, venous leg ulcers, diabetic foot ulcers, burns, surgical site

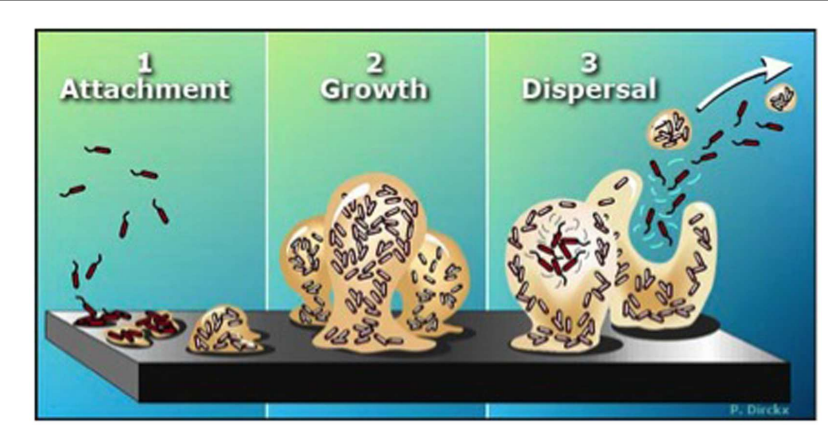

FIGURE 2 |The biofilm life cycle. (1) Free-floating (planktonic) bacteria encounter a submerged surface and within minutes can become attached. They begin to produce slimy extracellular polymeric substances (EPS) and start to colonize the surface. (2) EPS production allows the emerging biofilm community to develop a complex, three-dimensional structure that is influenced by a variety of environmental factors. Biofilm communities can develop within hours. (3) Biofilms can propagate through detachment of small or large clumps of cells, or by a type of "seeding dispersal" that releases individual cells. Either type of detachment allows bacteria to attach to a surface or to a biofilm downstream of the original community. [Biofilms: The Hypertextbook (http://www.hypertextbookshop.com/ biofilmbook/v004/r003/index.html). Used with permission from Montana State University Center for Biofilm Engineering].

infections, combat wounds, and other factors, suffer from persistent inflammation and are often infected with strong biofilmforming bacteria (James et al., 2008). Adding to the complexity is 
the finding that these infections are often composed of multiple microbial species attacking host cells, and thus antibiotic therapy that target specific bacteria becomes ineffective (Dowd et al., 2008). Moreover, the emergence of multi-drug-resistant strains of wound containing bacteria such as $S$. aureus (e.g., methicillin-resistant $S$. aureus, MRSA, and Acinetobacter baumannii) has intensified the need for new treatments.

Growing evidence supports the hypothesis that the presence of biofilm actively prevents the healing of these wounds (Figure 3 ) (Wolcott et al., 2010b). While physical debridement can assist the healing of chronic infected wounds, anti-biofilm approaches in combination with anti-inflammatory and antimicrobial therapy may promote more rapid healing in a broad range of chronic wound patients (Wolcott et al., 2009; Ammons, 2010). Wolcott and Dowd have shown in mouse models and human patients that elimination of biofilm from a wound promotes wound healing (James et al., 2008; Wolcott et al., 2008, 2010c; Dowd et al., 2009; Fisher et al., 2010; Lopez-Leban et al., 2010). The use of multiple concurrent strategies to treat these wounds is most effective, combining physical debridement, systemic antibiotics, and topical treatments that reduce biofilm. Once the biofilm collapses, the host immune system and the systemic antibiotics are able to combat the unprotected bacteria, the infection resolves, and the wound heals (Wolcott and Rhoads, 2008; Lopez-Leban et al., 2010; Wolcott et al., 2010a,b,c), even though diabetic patients often have impaired wound healing as part of the disease process.

Thus, the use of an anti-biofilm agent may represent an effective strategy to treat chronic infected wounds by enabling innate and adaptive immunity, as well as concomitant treatment with existing antibiotics to become more effective.

\section{ANTIMICROBIAL PEPTIDES}

Antimicrobial peptides are essential components of human innate immunity and contribute to the first line of defense against infection (Zasloff, 2002). There are currently over 1480 known AMPs with antibacterial, anticancer, antiviral, and antifungal activities

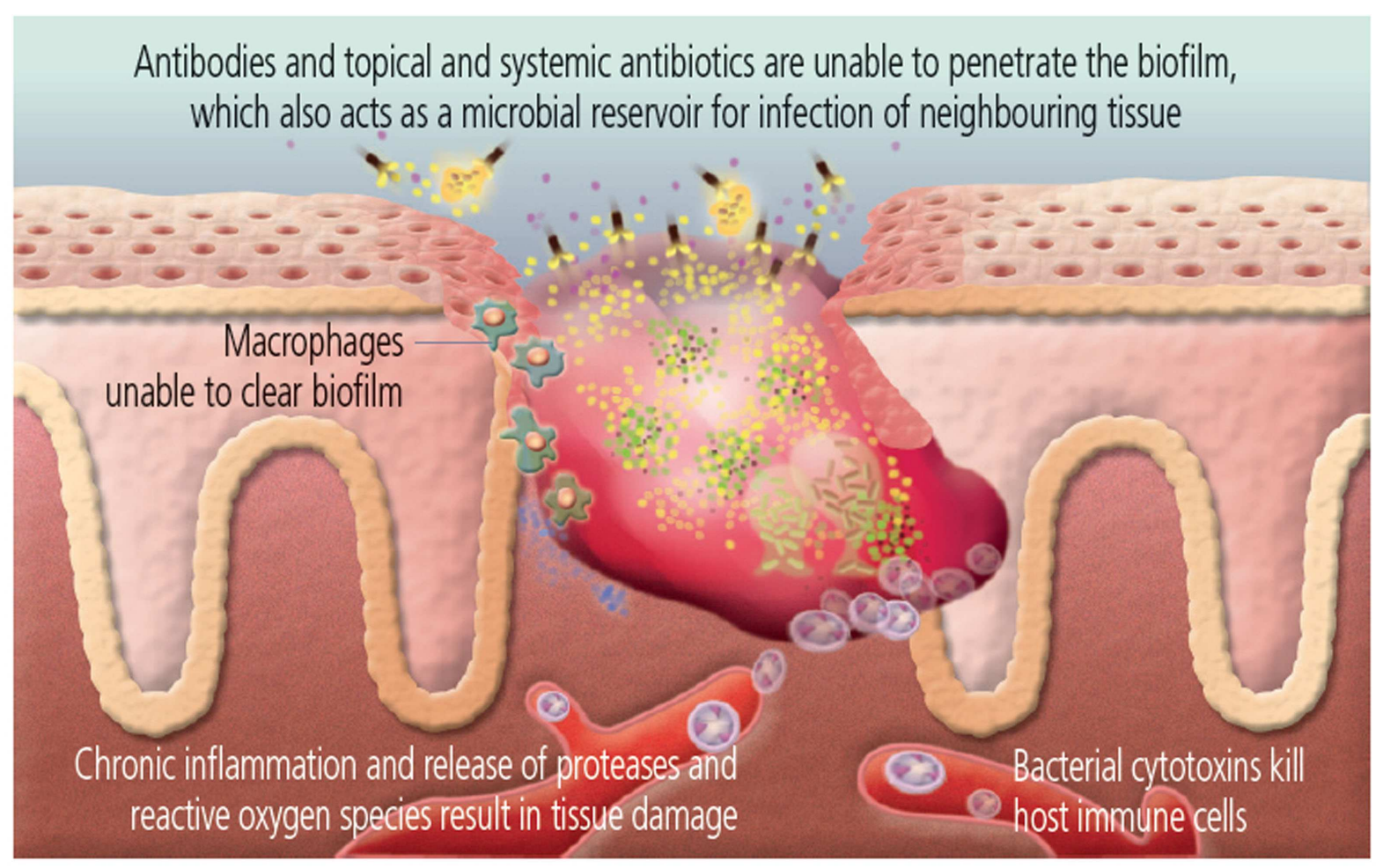

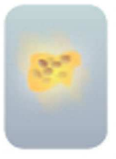
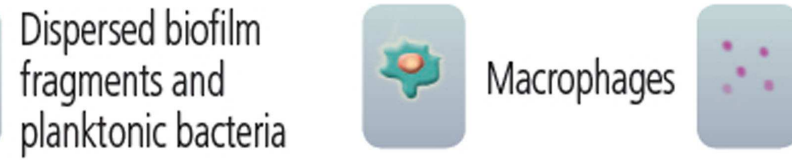

Antibiotics

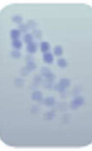

Host secreted proteases and reactive oxygen species

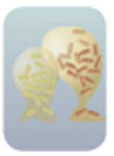

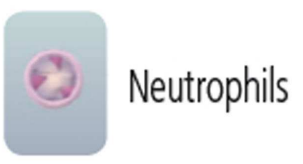

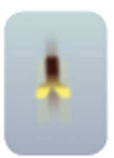

Antibodies

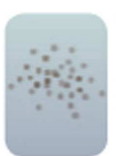

FIGURE 3 | Bacteria in the wound are protected by biofilm. [Image used with permission from Biofilms Made Easy, 2010, Vol. 1, Issue 1, published on Wounds International (http://www.woundsinternational.com/pdf/content_8851.pdf)]. 
(Wang et al., 2009). In general, many of these AMPs are cationic, amphipathic, between 12 and 100 amino acids in size, are structurally diverse and are capable of binding to and disrupting the membranes of microbes (Yeaman and Yount, 2003; Hurdle et al., 2011). AMPs can inhibit cell wall, nucleic acid, and protein biosynthesis (Brogden, 2005) and are chemotactic for many leukocytes, drawing them to the site of infection or inflammation. They have also been shown to be capable of binding and neutralizing lipopolysaccharides (LPS), promoting angiogenesis and wound healing, and exerting anti-tumor activity. Even though AMPs have co-evolved with bacteria over millions of years, bacteria have surprisingly not developed wide-spread resistance, providing AMPs with a potentially attractive advantage over existing antimicrobial agents.

\section{CATHELICIDINS}

The cathelicidin family of AMPs, named by the ability to inhibit the protease cathepsin-L, is a large and diverse group of peptides containing a conserved N-terminal domain called the cathelin domain. Cathelicidins can be found in their precursor form in the granules of natural killer $\mathrm{T}$ cells, neutrophils, and in the mucosal epithelia of the lungs, with the functional antimicrobial cathelicidin peptide generated through proteolytic removal of the cathelin domain as part of the secretion process (Bals, 2000). This class of peptides has been shown by us and many other researchers to be antimicrobial against many human bacterial pathogens (Amer et al., 2010; de Latour et al., 2010; Dean et al., 2011a,b; Jiang et al., 2011; Kanthawong et al., 2012). The sequence diversity of cathelicidins resides in the active peptide following cleavage of the conserved $\mathrm{N}$-terminus, and thus cathelicidins are structurally conserved AMPs containing amphipathic $\alpha$-helices without sequence conservation.

In humans, the cathelicidin gene encodes an inactive $18 \mathrm{kDa}$ precursor protein (Hcap-18) that releases the active Cterminus 37 amino acid peptide LL-37 (LLGDFFRKSKEKIGKEFKRIVQRIKDFLRNLVPRTES) upon processing. Overviews of the structural properties, expression, cellular and tissue distribution, and antimicrobial, chemotactic, and immunomodulatory activities of this intriguing class of peptide have been published (Durr et al., 2006; Kai-Larsen and Agerberth, 2008; Burton and Steel, 2009; Nijnik and Hancock, 2009; Mendez-Samperio, 2010; Jacobsen and Jenssen, 2012; Vandamme et al., 2012). This review will focus on the recent reports of LL-37 and its interactions with bacteria, biofilm, and host cells making it a potentially effective agent for the treatment of chronic non-healing wounds.

\section{LL-37 PEPTIDE}

\section{LL-37 STRUCTURE}

In order to begin to understand how LL-37 interacts with biofilms, bacteria, and host cells, it is important to consider its features and secondary structure. Fifty-four percent of LL-37's residues are hydrophilic with 11 basic and 5 acidic, giving it a net positive charge of +6 at physiological $\mathrm{pH}$. In aqueous solution LL-37 exhibits a circular dichroism spectrum that is consistent with a disordered structure (see Table 1, entry A). However, in membranes where the environment is lipophilic, many of the amino acids are able to form intramolecular hydrogen bonds (backbone $\mathrm{N}-\mathrm{H}$ groups donate a hydrogen bond to the backbone $\mathrm{C}=\mathrm{O}$ groups that are four amino acids earlier in the sequence) locking the secondary structure into an $\alpha$-helix (Dean et al., 2011a).

A characteristic feature of the LL-37 $\alpha$-helix is its amphipathic nature, illustrated by the helical wheel and molecular model diagrams in Table 1, entries B and C, respectively. The secondary structure, while viewing into the coil, reveals a lipophilic side and a polar side that is positively charged (cationic) at physiological $\mathrm{pH}$ (7.4). In efforts to more accurately approximate the conformation of LL-37 in membranes, the three-dimensional NMR structure was elucidated in dodecylphosphocholine micelles (Porcelli et al., 2008). Under these conditions, both the $\mathrm{N}$ - and C-termini were unstructured and solvent exposed, and the $\mathrm{N}$ - and C-terminal helixes were hinged at K12, supported by a hydrophobic cluster formed by I13, F17, and I20, and a salt bridge between K12 and E16 (see Table 1, entry D). The hydrophilic face of LL-37 was exposed to the water phase and the hydrophobic face was buried in the micelle hydrocarbon region. In a similar fashion, a threedimensional triple-resonance NMR spectroscopy study of LL-37 in SDS micelles was performed (Wang, 2008). Under these conditions a curved amphipathic helix-bend-helix motif was found that spanned residues 2-31, and the C-terminal tail was disordered (Table 1, entry E). The extent of $\alpha$-helicity appears to correlate with the antibacterial activity of LL-37 against both Gram-positive and Gram-negative bacteria (Johansson et al., 1998).

Structural information along with structure activity relationships around LL-37 and its smaller fragment derivatives continue to emerge. For a comprehensive review of the sequence and bioactivity of published native fragments and synthetic analogs of LL-37 (see Burton and Steel, 2009). A number of these smaller peptidic analogs have similar antimicrobial activities compared with LL37 , but are less cytotoxic and more stable in the presence of serum (Ciornei et al., 2005), and thus may be useful tools for evaluating AMPs in the treatment of chronic infected wounds.

\section{LL-37 ENDOGENOUS LEVELS}

The LL-37 peptide is produced by proteolytic cleavage (Protease 3 ) of hCAP-18 that exists at high concentrations in the granules of neutrophils $\left(40 \mu \mathrm{M}\right.$ or $630 \mu \mathrm{g} 10^{9}$ cells) (Sørensen et al., 1997, 2001). However, in skin the serine proteases SCTE (stratum corneum tryptic enzyme, kallikrein 5), SCCE (stratum corneum chymotryptic enzyme, kallikrein 7), and kallikreinrelated peptidase-8 (KLK8) were shown to control activation of hCAP-18 and influence further processing to smaller peptides with alternate biological activity (Yamasaki et al., 2006; Eissa et al., 2011). In support of this finding, doxycycline and other matrix metalloproteinase inhibitors were recently found to inhibit the generation of LL-37 from hCAP-18 in keratinocytes, a process dependent on kallikrein activity (Kanada et al., 2012). The physiological concentration of LL-37 varies within different tissues and cells, and is often altered at sites of infection. For example, LL-37 levels were significantly elevated in serum specimens from multiply injured patients $(0.02 \sim 0.04$ vs. $0.002 \mu \mathrm{M}$ for controls) (Lippross et al., 2012), and LL-37 was highly expressed in the skin of psoriasis patients (Reinholz et al., 2012). More relevant to chronic infected wounds, LL-37 expression was lower in keloid and atopic dermatitis patients compared with normal 
Table 1 | Secondary structure of LL-37.

\section{LLGDFFRKSKEKIGKEFKRIVQRIKDFLRNLVPRTES}

A

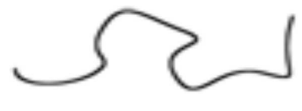

$-$

B

\section{LL-37 sequence}

LL-37 in aqueous media has no defined conformation

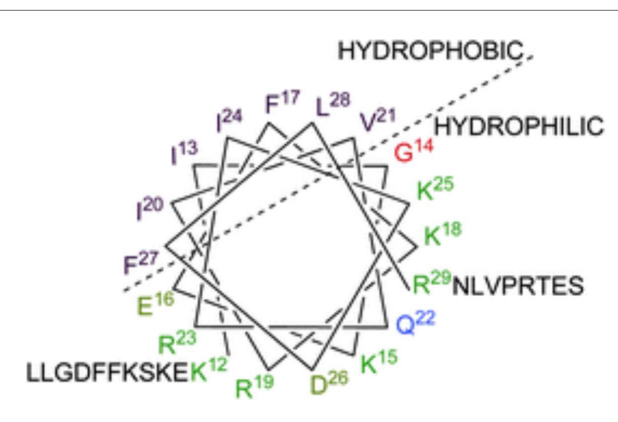

C

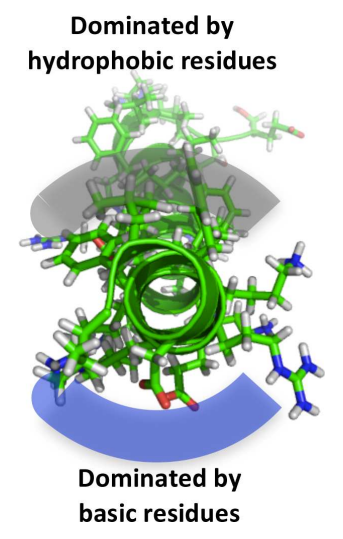

D

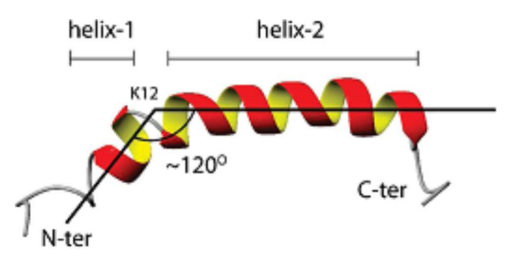

E

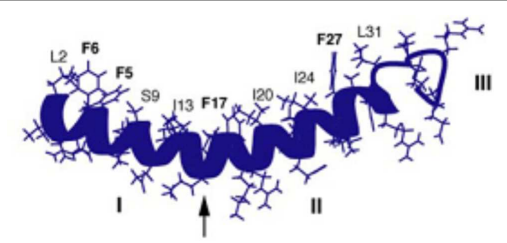

(Park et al., 2009), and in the epidermis of diabetic foot ulcers and chronic venous ulcers LL-37 had little to no expression compared to healthy skin (Rivas-Santiago et al., 2012). This later data may imply that part of the issue contributing to the chronic infection present in non-healing wounds may be the low levels of the innate immune system peptide LL-37.

Unbound LL-37 levels in the wound are regulated by a balance of expression, degradation, and serum (or wound exudate)
Helical wheel diagram for LL-37 showing the region 12-29 as an amphipathic helix. N- (residues 1-11) and C- (residues 30-37) termini residues are unstructured (Burton and Steel, 2009)
View of AMP looking through the coil showing its amphipathic nature LL-37 structure from PDB 2K6O. Image generated using MacPyMol
NMR structure of LL-37 in dodecylphosphocholine micelles showing the angle between the two helical domains and the break point centered at K12 (Porcelli et al., 2008) protein binding. Adding to the complexity, the pathogen itself, through LPS found in the outer membrane of Gram-negative bacteria can induce the expression of LL-37. This induction occurs via interaction at the toll-like receptor 4 (TLR4) and through subsequent release of cytokines such as IL- 4 , IL-5, IL- $1 \beta$, and TNF- $\alpha$. As a counteraction, LL-37 in turn can bind to LPS and prevent its interaction with lipopolysaccharide-binding protein (LBP) and the co-receptor CD14, thus neutralizing the effect of LPS 
(Nagaoka et al., 2001; Yoshioka et al., 2008). In general, the release of the LL-37 peptide in the wound is a physiological response to host/pathogen induced TLR and NOD-like receptor (NLR) signals (Thoma-Uszynski et al., 2001).

LL-37 antibacterial activity was found to be unaffected by the presence of $50 \%$ serum, citrate-plasma, or EDTA-plasma. However, heparin-plasma and wound fluids that contain glycosaminoglycans (GAGs) (e.g., dermatan sulfate) attenuated the antibacterial effects of LL-37. These effects could be abrogated by the addition of polycationic polysaccharides (e.g., chitosan) that form complexes with GAGs (Baranska-Rybak et al., 2006). In infected wounds, bacteria such as $P$. aeruginosa were able to release GAGs from connective tissues and block the bactericidal actions of LL-37. In addition, $P$. aeruginosa elastase is a secreted protease that has been shown to further deactivate LL-37 by cleaving it at many of the amino acid junctions (Schmidtchen et al., 2002). Within host cells, mast cell activation by LL-37 results in the release of mast cell protease ( $\beta$-tryptase) that degrades and inactivates LL-37. However, in this case as a counter-regulation, the platelet-derived chemokine, CXCL4, protects LL-37 from cleavage by $\beta$-tryptase by antagonizing the heparin component required for the integrity of the active tetramer of $\beta$-tryptase (Schiemann et al., 2009).

Noteworthy, since protease cleavage typically occurs between natural amino acids, the incorporation of unnatural amino acids can be used as a strategy to improve metabolic stability. For example, the unnatural enantiomer D-LL-37 (in which each amino acid is in the D-configuration) was found to be resistant to trypsin degradation (Figure 4) (Dean et al., 2011a). In ex vivo experiments, LL-37 was degraded by trypsin, but its susceptibility to trypsin was diminished in the presence of wound fluid up to $24 \mathrm{~h}$
(Gronberg et al., 2011). Thus, the protein binding of LL-37 in wound fluid may protect it from protease degradation. Regardless, there may be significant benefit to using protease-resistant analogs of LL-37 in vivo to prolong the effective half-life. To that end, we have performed in vivo studies using the wax moth caterpillar and demonstrated an increased survival of Pseudomonas infected caterpillars following D-LL-37 treatment (Figure 6) (Dean et al., 2011a). These results suggest that D-LL-37 may be more effective at rescuing caterpillars from Pseudomonas infection, likely due to its improved protease resistance.

In leukocytes and keratinocytes, the mechanisms regulating LL37 production have been linked to vitamin D3. Induction of LL-37 by 1,25-dihydroxyvitamin D3 requires the intracellular vitamin $\mathrm{D}$ receptor (VDR), as well as the steroid receptor coactivator 3 (SRC3) and histone acetylation (Schauber et al., 2008). Thus, the host/pathogen response to the regulation of LL-37 is complex.

\section{LL-37 MECHANISM OF INTERACTION WITH MICROBIAL MEMBRANES}

LL-37 has broad-spectrum antimicrobial activity against both Gram-negative and Gram-positive bacteria (Durr et al., 2006) including drug-resistant strains (Saiman et al., 2001; Zaiou et al., 2003; Schittek et al., 2008). AMPs, and LL-37 in particular, have a different mode of action compared to conventional antibiotics as its size, shape, lipophilicity, and cationic nature interacts with the lipophilic and anionic nature of LPS, a component of the outer membrane of most Gram-negative bacteria (Figure 5). Using fluorescence microscopy, the antimicrobial activity of LL-37 attacking the Gram-negative bacteria E. coli was recently dissected into stages (Sochacki et al., 2011). The first stage was binding to the outer membrane and its LPS and O-antigen layers, which quickly saturate. At $8 \mu \mathrm{M}, \mathrm{LL}-37$ binding saturated the outer membrane

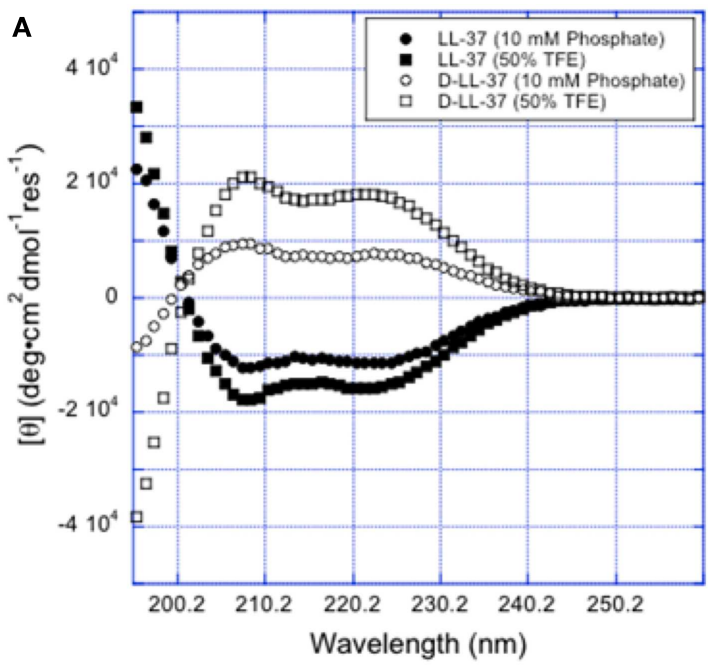

FIGURE 4 | Chirality affects LL-37 susceptibility to proteases. (A) The spectra for I- and d-LL-37 (125 $\mu \mathrm{M})$ exhibit significant helical character in $10 \mathrm{mM}$ sodium phosphate buffer $(\mathrm{pH}=7.4)$. As expected, the spectrum for $d-L L-37(\bullet)$ is the mirror image of that of the l-peptide (o). The spectra for both $\mathrm{d}$ - and I-LL-37 ( $\square$ and $\mathrm{n}$ respectively) become more intense when the peptides are in $50 \%$ TFE in $10 \mathrm{mM}$ phosphate buffer $(\mathrm{pH}=7.4)$, consistent with the peptides exhibiting more helical character in the presence of these

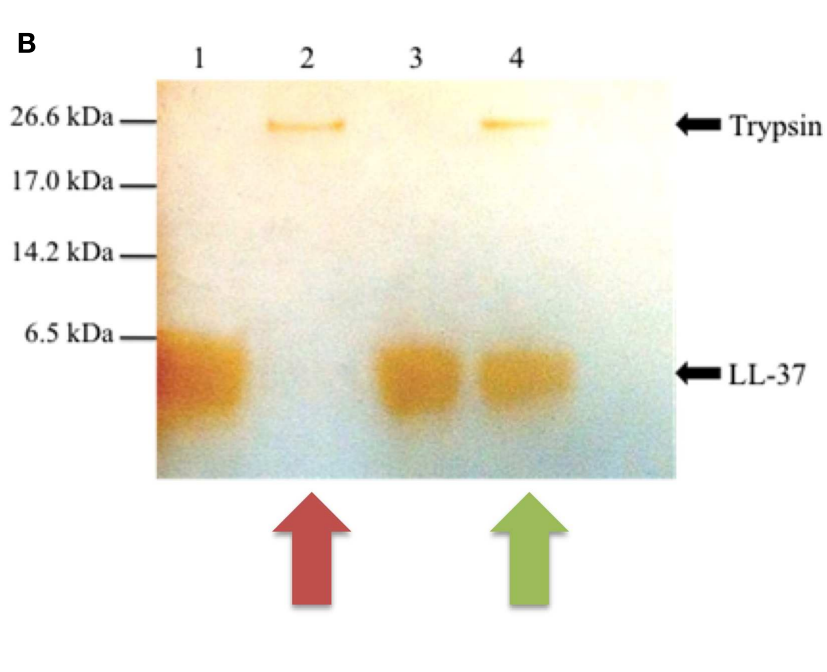

membrane-mimics. These results are consistent with what has been reported in the literature for these peptides. (B) $d$-LL-37 demonstrated resistance to degradation by trypsin. Peptides $(18 \mu \mathrm{g})$ were dissolved in water $(90 \mu \mathrm{L})$ with either water or $0.05 \% \operatorname{trypsin}(10 \mu \mathrm{L})$ and incubated $\left(37^{\circ} \mathrm{C}, 1 \mathrm{~h}\right)$. Ten microliters of aliquots were separated on SDS-PAGE, and a silver stain was performed. Lane 1, LL-37; Lane 2, LL-37 with trypsin; Lane 3, d-LL-37; Lane 4, d-LL-37 with trypsin. (Figure from Dean et al., 2011a, used with permission). 
within $1 \mathrm{~min}$. Translocation across the outer membrane and access to the periplasmic space correlated in time (5-25 min later) with the halting of growth, which may occur because of LL-37 interference with cell wall biogenesis. As shown in Figure 5, after membrane association there are several proposed models of how the AMP may induce bacterial killing (for an overview see Brogden, 2005). In the barrel-stave model, the LL-37 peptides would attach, aggregate, and insert into the inner membrane bilayer with the hydrophobic side of the peptide aligning with the lipid core region and the hydrophilic side forming the interior region of the pore (Table 1, B and C). In the Toroidal model, the attached LL-37 peptides would aggregate and bend the lipid monolayers continuously through the pore so that the core would become lined by the head groups of both the inserted peptides and the lipid monolayer. In the carpet model (micelle formation), the LL-37 peptides would disrupt the membrane by orienting parallel to the surface of the lipid bilayer and form an extensive layer or carpet. In all cases, the interaction would result in pores being formed within the inner membrane followed by bacterial lysis.

LL-37 and its LL-31 truncated analog (lacking the 6 C-terminus residues) exhibited a strong killing effect against Burkholderia pseudomallei (Kanthawong et al., 2012). The percentage of $\alpha$ helical structure as determined by circular dichroism was similar for LL-37 vs. LL-31. In this study, the killing of B. pseudomallei (as well as $B$. thailandensis) was shown to be caused by disruption of membrane as measured by freeze-fracture electron microscopy of bacterial cells. Both peptides exhibited stronger antimicrobial activity against B. pseudomallei in biofilm compared to ceftazidime, a cephalosporin antibiotic that is used clinically for initial melioidosis treatment. This result is consistent with LL-37's ability to permeabilize and/or to form pores within the cytoplasmic membrane.

In recent studies, LL-37 has also been shown to have specific binding interactions with the outer membrane lipoprotein Lpp in Enterobacteriaceae (Chang et al., 2012). Lpp is composed of trimeric $\alpha$-helices (in aqueous solution) (Shu et al., 2000), and although proposed to act as a barrier against antibiotics, there is evidence that LL-37 binds and internalizes Lpp. The crystal structure of Lpp provides an explanation for assembly and insertion of the lipoprotein molecules into the outer membrane of Gramnegative bacteria. The authors suggest that the susceptibility of bacteria to an AMP is not strictly correlated with the presence of Lpp on bacteria, as the bactericidal activities were blocked by anti-Lpp antibodies. As specific receptors and mechanisms for which LL-37 interacts with bacteria are gradually becoming understood, it is clear that further research is warranted in the area.

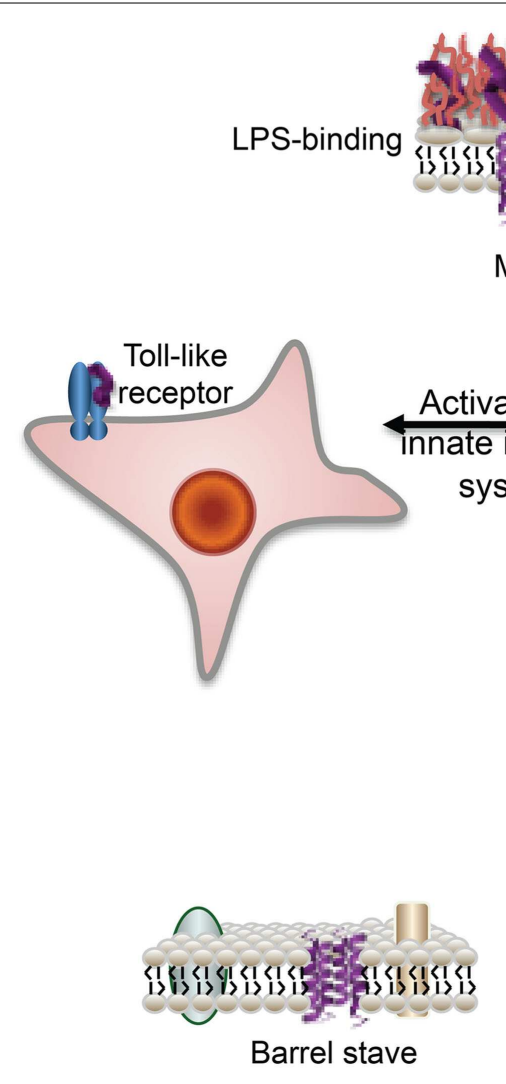

FIGURE 5 | Overview of the broad-spectrum of cellular interactions associated with antimicrobial peptides. In addition to exerting antimicrobial activity by disrupting bacterial membranes, peptides may also bind to specific target proteins within microbial cells and activate the innate immune system. The binding of peptides to cell-surface LPS molecules and proteolysis contribute to bacterial resistance to AMPs (From Marsh et al., 2009, reproduced by permission of the Royal Society of Chemistry). 


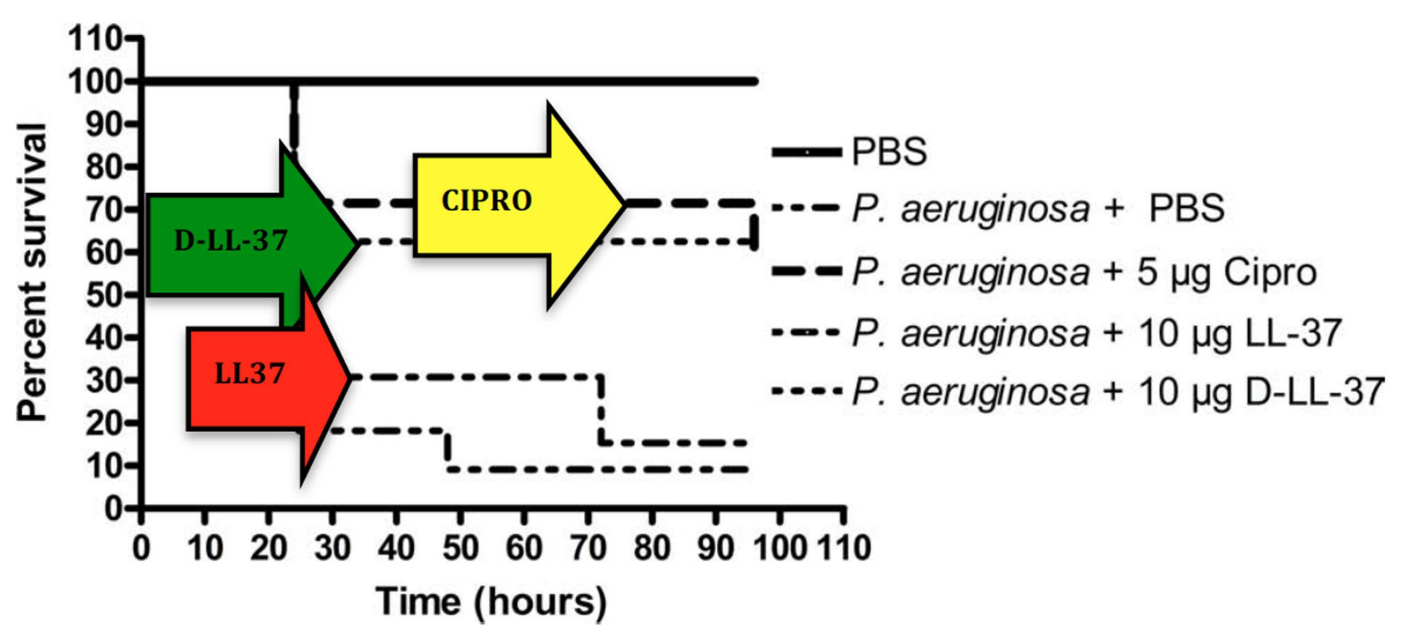

FIGURE 6 | Treatment of $\boldsymbol{P}$ aeruginosa-infected $\boldsymbol{G}$. mellonella. d-LL-37 significantly prolonged the survival of $G$. mellonella infected with $1 \times 10^{3} \mathrm{CFU}$ $P$. aeruginosa. Non-infected control groups consisted of a PBS injection, $5 \mu \mathrm{g}$ Ciprofloxacin injection, $10 \mu \mathrm{g} \mathrm{LL}-37$ injection, or a $10 \mu \mathrm{g} \mathrm{d}$-LL-37 injection. All non-infected groups fare similarly to the PBS only group (data not shown). The non-infected PBS only group experienced the highest survival rate and was significantly different from all other groups ( $p$-value $<0.002$ ). The infected group without treatment failed to survive beyond $24 \mathrm{~h}$. A single dose of $5 \mu \mathrm{g}$ ciprofloxacin, or $10 \mu \mathrm{g}$ of either $\mathrm{d}$ - or I-LL-37 was found effective when compared to the infected control group ( $p$-value $<0.01$ ), but not different from each other overall. At $48 \mathrm{~h}$ d-LL-37 was found to be more effective than I-LL-37 (p-value < 0.04). (Figure from Dean et al., 2011a, used with permission).
Finally, for some AMPs, there is a mechanism by which the peptide can penetrate the bacterial cell and potentially act directly on intracellular targets, though primarily to be nucleic acids (DNA or RNA) (Takeshima et al., 2003; Lan et al., 2010; Madani et al., 2011). Recent studies suggest that LL-37 may be able to be a cell-penetrating peptide as well (Zhang et al., 2010; Hoyer et al., 2012).

\section{LL-37 ANTI-BIOFILM ACTIVITY}

One of our long term goals is to discover new treatments for polymicrobial infected wounds, which are often biofilm-mediated (Edwards and Harding, 2004). These wounds are most often infected with multiple bacteria (polymicrobial) and usually produce a large amount of biofilm as part of the pathology of the infection. New treatments for non-healing infected chronic wounds are a high need, especially in light of emerging antibiotic resistant organisms.

The mechanism by which LL-37 carries out its anti-biofilm effect is unknown for the case of S. aureus, and is suggested as the dysregulation of biofilm regulatory systems and quorum-sensing in P. aeruginosa (Overhage et al., 2008). Thus, several mechanisms for anti-biofilm activity are possible. For example: prevention of twitching and/or the initial attachment; membrane perturbation leading to an SOS response (Coenye, 2010); and blocking intracellular quorum-sensing molecules. Interestingly, LL-37 potently inhibited the formation of bacterial biofilms, including $S$. aureus (Dean et al., 2011b), and P. aeruginosa in vitro at concentrations $(0.5 \mu \mathrm{g} / \mathrm{ml})$ far below that required to kill or inhibit bacterial growth (MIC $64 \mu \mathrm{g} / \mathrm{ml}$ ) (Overhage et al., 2008; Dean et al., 2011a). In this example the anti-biofilm activity was demonstrated to be mediated in three ways: (a) reduction of the initial attachment of $P$. aeruginosa cells to the surface; (b) promotion of twitching by stimulating the expression of genes related to type IV pilus biosynthesis and function (increased surface motility would cause bacteria to wander across the surface instead of forming biofilms); and (c) down-regulation of key components of the Las and Rhl systems (quorum-sensing systems of $P$. aeruginosa). The ability of LL-37 to inhibit biofilm formation, especially at physiologically relevant concentrations, is a promising feature with regards to the treatment of chronically infected wounds.

The connection between biofilm formation and hard-toheal wounds was demonstrated in a murine cutaneous wound model where Staphylococcal biofilms were shown to delay reepithelialization. In this experiment, the disruption of the quorum-sensing system through the addition of RNAIII inhibiting peptide (RIP) (breaking the cycle of biofilm signaling) restored normal wound healing (Schierle et al., 2009). It is important to point out that even though RIP is neither bactericidal nor bacteriostatic (Kiran et al., 2008), it reduced the ability of bacteria to survive within the host. In other words, "when the biofilm collapses, the once protected bacterial community can be targeted by the immune system and by antibiotics, allowing complete recovery of the otherwise non-healing wound" (Wolcott et al., 2011). With respect to the LL-37 peptide, in addition to its ability to be antibiofilm and antimicrobial, it plays an important role in regulating the balance of pro- and anti-inflammatory molecules both under homeostatic conditions and during bacterial or endotoxin challenge (Mookherjee et al., 2006). LL-37 peptide thus demonstrates broad-spectrum antimicrobial and anti-biofilm properties (Overhage et al., 2008; Dean et al., 2011a,b), making it a strong candidate to develop into a topical therapeutic for infected combat or burn wounds or chronic, non-healing wound such as diabetic ulcers.

Methods for screening new molecules for anti-biofilm activity in an in vitro model of an infected wound are available. For example, the Lubbock chronic wound biofilm model is an in vitro multispecies biofilm model that simulates the functional 
characteristics of chronic pathogenic biofilms (Sun et al., 2008). Visually, as well as by electron microscopy, this model is morphologically similar to actual chronic wound biofilms and shows promise as a tool for discovering new anti-biofilm agents.

It may be more appropriate to refer to these peptides as "anti-biofilm peptides" rather than "AMPs," reflecting our current understanding of the potential role of biofilms in infection. Incorporation of anti-biofilm peptides or their synthetic derivatives in therapeutic topical applications may improve outcomes for infections ranging from chronic wounds, burns, implanted medical devices, and pneumonia.

\section{LL-37 INTERACTION WITH HOST CELLS}

The interactions of LL-37 with host cells are numerous and complex and not completely understood. LL-37 was shown to have a chemotactic effect on inflammatory cells, and depending on its concentration has shown a remarkable ability to modulate their effects. As previously mentioned, hCAP-18/LL-37 is stored predominantly in human neutrophil granules, but also in T cells, monocytes, lymphocytes, natural killer cells, B cells, and mast cells. In wounds, LL-37 is secreted in wound fluid and sweat, and is upregulated in response to infection. It is interesting that at different concentrations LL-37 can have opposing effects on host cells. For example, LL-37 exposures that were at or below $\sim 1 \mu \mathrm{M}$ enhanced neutrophil survival and increased fibroblast migration and proliferation. In contrast, higher concentrations were cytotoxic (enhanced apoptosis) and amplified an acute inflammatory response (Oudhoff et al., 2010). Reported activities and effects of LL-37 at particular concentration levels are shown in Figure 7. As development of these peptides continues it is important to view the overall effects of LL-37 at $0.2 \sim 1 \mu \mathrm{M}$, concentrations at which wound-healing effects are observed.

In addition, shorter peptides may also prove useful to retain antimicrobial activity and potentially have less host-toxicity. The cathelicidin LL-37 and shorter derivatives were tested for toxicity (oto-toxicity, primary skin irritation/corrosion, acute eye irritation, and toxicity by repeated dose administration in rats), and no toxicity was found for P60.4, a 24aa acetylated and amidated peptide derivative of LL-37 (Nell et al., 2006).

Mechanistically, LL-37 has been shown to use formyl protein receptor like 1 (FPRL-1), a cell surface GPCR, to chemoattract human peripheral blood neutrophils, monocytes, and T cells (Yang et al., 2000). The suppression of neutrophil apoptosis below $1 \mu \mathrm{M}$ was shown to occur through the activation of FPRL- 1 and P $2 \times 7$, and antagonists of these receptors attenuated the suppression (Nagaoka et al., 2006). By direct activation of the $\mathrm{P} 2 \times 7$ receptor, LL-37 stimulated IL-1 $\beta$ secretion from monocytes (Elssner et al., 2004). In line with the $\mathrm{P} 2 \times 7$ receptor mechanism, LL-37 induced pore formation and release of intracellular ATP as evidenced by the uptake of the fluorescent nucleic acid dye, YO-PRO-1. Known inhibitors of the $\mathrm{P} 2 \times 7$ receptor (KN04, KN-62, and oxidized ATP) inhibited IL-1 $\beta$ processing and release induced by LL-37 in a dose-response fashion. It was noted that this effect did not appear to be due to increased endogenous ATP since (a) this increase in response to LL-37 was only in the 100-200 nM ATP range (mM ATP levels are needed to activate IL-1 $\beta$ release) and (b) apyrase, which catalyzes the hydrolysis of ATP, completely

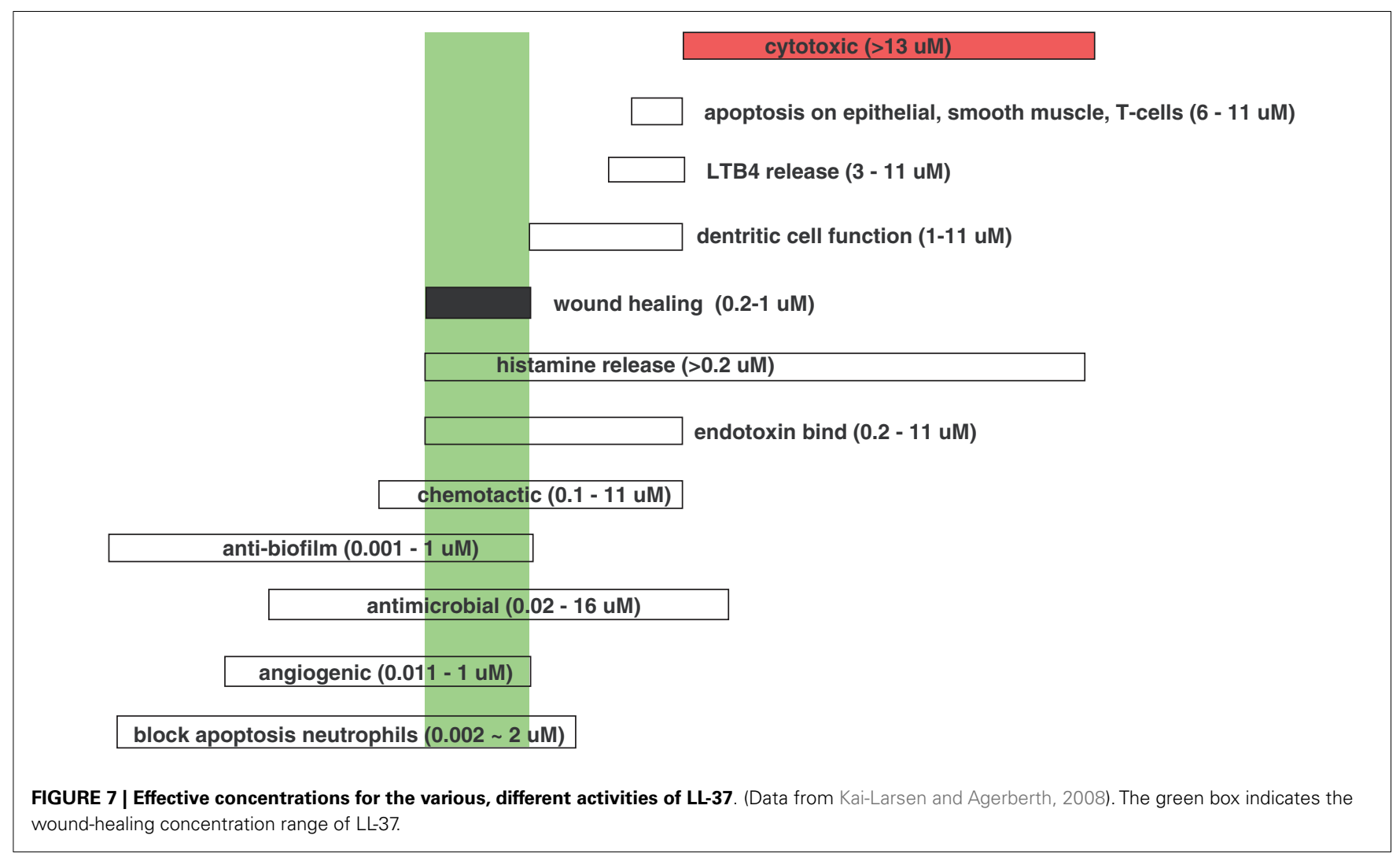


inhibited exogenously added ATP $(5 \mathrm{mM})$, but did not block IL-1 $\beta$ release from LL-37 stimulated cells (Wewers and Sarkar, 2009).

On a molecular level, LL-37's ability to insert deeply into host cell membranes may support the hypothesis that the functional interaction between LL-37 and P2 $\times 7$ involves transmembrane segment-mediated binding. This may also explain the finding that D-LL-37 has similar activity to LL-37 in modulating the P2 $\times 7$ receptor (Tomasinsig et al., 2008) and at inhibiting Pseudomonas biofilm formation (Dean et al., 2011a), especially since the hydrophobic environment of the membrane allows for specific interactions to be formed between polypeptides irrespective of their chirality.

In the presence of Gram-negative bacteria, LL-37 was able to interact directly with LPS to reduce its binding to LBP, MD2, or other components of the TLR4 receptor complex, thus reducing activation of the downstream pathway (Scott et al., 2000). LL-37 also inhibited LPS-induced translocation of the NF-kB subunits p50 and p65, and selectively modulated gene transcription, completely inhibiting certain pro-inflammatory genes (p50, TNFAIP2) and reducing the expression of others (TNF- $\alpha$ ) (Bowdish et al., 2004). LL-37 was also shown to directly trigger MAPK pathways that can in turn impact pro-inflammatory pathways. In other reports, LL-37 has been shown to activate mast cells via mas-related Gene X2 (MrgX2, a novel GPCR) (Subramanian et al., 2011), and may act as a functional ligand for CXCR2 on human neutrophils (Zhang et al., 2009). Thus, LL-37 has a diverse and potentially advantageous immunemodulating effect on host cells within the wound environment.

\section{LL-37 AND WOUND HEALING}

The resistance of chronic wounds to heal has been shown to be associated with the presence of multispecies pathogenic biofilms. As previously stated, once biofilm is broken down, the underlying bacterial colonies can be targeted by the immune system as well as by antibiotics, potentially allowing recovery of the otherwise non-healing wound. LL-37 is capable of performing all of these functions (anti-biofilm, antimicrobial, immune-modulating), and when administered topically, can potentially avoid the many hurdles of systemic peptide delivery.

An intriguing aspect of LL-37 with respect to skin wounds is its interaction with keratinocytes. Keratinocytes, the predominant cell type found in the epidermis, form barriers against microbial pathogens during wound closure, and keratinocyte migration is an important step in skin wound healing. Growth factors important to wound healing (IGF-1 and TGF- $\alpha$ ) induced the expression of hCAP-18/LL-37 in human keratinocytes (Sørensen et al., 2003) and the P2 $\times 7-$ SFK-AktCREB/ATF1 signaling pathway activated by LL-37 in keratinocytes was established (Nijnik et al., 2012). In a Boyden chamber assay, LL-37 $(1 \mu \mathrm{g} / \mathrm{ml})$ induced the maximum level of keratinocyte migration, and this was shown to progress via EGFR transactivation (Tokumaru et al., 2005). LL-37 was also found to protect human keratinocytes from apoptosis via the activation of the COX-2 pathway (Chamorro et al., 2009). hCAP-18 is strongly expressed in healing skin epithelium, and treatment with antibodies raised and affinity purified against LL-37 inhibited re-epithelialization (wound closure) in a concentrationdependent manner (Heilborn et al., 2003). Adenovirus-mediated LL-37 gene transfer was found to promote wound healing in diabetic ob/ob mice by increasing the re-epithelialization rate and granulation tissue formation (Carretero et al., 2008). In vivo, cathelicidin-deficient mice were shown to be more susceptible to group A Streptococcus infection compared to normal mice, supporting the involvement of epithelial cellderived cathelicidin in host immune defense (Braff et al., 2005).

Fibroblasts, another epidermal cell, also play a key role in tissue repair because they change their phenotype during the late phase of repair and begin to proliferate and synthesize large amounts of extracellular matrix which is crucial for wound resolution. LL-37 can induce fibroblast proliferation, and the stimulation of fibroblast growth by LL-37 was inhibited by KN-62 (P2 × 7R antagonist), supporting a role for the $\mathrm{P} 2 \times 7 \mathrm{R}$ pathway (Tomasinsig et al., 2008) in this process.

In other models, LL-37 stimulated the healing of mechanically induced wounds in monolayers of human epithelial lung cells (NCI-H292 cells) $(5 \mu \mathrm{g} / \mathrm{ml})$ and in differentiated primary airway epithelium $(1 \mu \mathrm{g} / \mathrm{ml})$. These effects were shown to be mediated through epidermal growth factor receptor, a GPCR, and MAP/extracellular signal-regulated kinase (ERK) (Shaykhiev et al., 2005). Similar signaling was reported within oncology research, where LL-37 was found to have affinity to the insulin-like growth factor 1 receptor (IGF-1R) resulting in phosphorylation of IGF-1R with downstream signaling of the mitogen-activated protein kinase/ERK pathway (Girnita et al., 2012). In summary, LL-37 induces signal transduction in the host cells that may contribute to the cellular processes involved in promoting wound healing.

\section{CLINICAL DEVELOPMENT}

The use of topical cationic peptides to treat bacterial infection has precedent and in recent years there have been a number of AMPs entering clinical trials. For example, the peptide omiganan (MBI 226), a 12-residue amide derivative of indolicidin (a cathelicidin isolated from bovine neutrophils), is in late-stage development as a topical antimicrobial for the prevention of local catheter-site infections (Ross et al., 2007). Peptide mimetics of AMPs (Flemming et al., 2009) have also progressed into clinical trials. Lytixar (LTX 109) is a synthetic antimicrobial peptidomimetic currently in phase II trials for the topical treatment of infections of multi-resistant bacterial strains (Isaksson et al., 2011). Another example, PMX-30063, is a defensin mimetic that is currently being evaluated in patients with acute bacterial skin infections (Morrisey et al., 2012). PMX-30063 showed potent activity against the Gram-positive bacteria tested, particularly Staphylococci, and the activity was unaffected by resistance to existing antibiotics, including MDR Staphylococci. Lactoferrin, another AMP, has shown efficacy against Pseudomonas biofilms (Kamiya et al., 2012). Treatment of Pseudomonas biofilm with lactoferrin in combination with xylitol led to both structural disruption of the preformed 
biofilm, as well as a reduction of viable bacteria through membrane permeabilization (Ammons et al., 2009, 2011). The RIP has shown effectiveness against severe polymicrobial infections (Lopez-Leban et al., 2010). Although no data has yet been published, LL-37 itself is currently in early development for the treatment of hard-to-heal wounds and a clinical study in venous leg ulcer patients is scheduled (Development Program LL-37, 2012). Thus, the use of peptides as a therapeutic approach for chronic infected wound treatment is beginning to be explored in the clinic, and this novel approach will hopefully lead to new and effective therapies for these difficult to treat conditions. Incorporation of anti-biofilm peptides or their synthetic derivatives in therapeutic topical applications may improve outcomes for infections ranging from chronic wounds, burns, implanted medical devices, and pneumonia.

\section{CONCLUSION AND DEVELOPMENT CHALLENGES}

Novel treatments for chronic wounds, pneumonia, and medical implant-associated infections are critically needed. These infections are often characterized by polymicrobial infections mediated by biofilm-forming bacteria, including $P$. aeruginosa (James et al., 2008). Desired characteristics of a novel therapeutic for these wounds would include a broad-spectrum, anti-biofilm treatment that is capable of withstanding the host environment, including protease and wound-exudate secretions.

Overall, LL-37 and other AMPs (Chalekson et al., 2002; Hirsch et al., 2009) appear to be promising for the treatment of chronically infected wounds since their anti-biofilm properties coupled with the combination of host and pathogen effects should act in harmony to expose and clear the underlying bacteria, and the peptide interaction with keratinocytes and fibroblasts should encourage wound closure. Proteolytic cleavage and systemic toxicity are two concerns with the development of peptides, but in the case of wound treatment, topical administration should lower these hurdles, especially in light of LL-37's demonstrated stability in wound exudate. We previously demonstrated the effectiveness

\section{REFERENCES}

Abee, T., Kovács, A. T., Kuipers, O. P., and van der Veen, S. (2011). Biofilm formation and dispersal in Gram-positive bacteria. Curr. Opin. Biotechnol. 22, 172-179. doi:10.1016/j.copbio.2010.10.016

Amer, L. S., Bishop, B. M., and van Hoek, M. L. (2010). Antimicrobial and antibiofilm activity of cathelicidins and short, synthetic peptides against Francisella. Biochem. Biophys. Res. Commun. 396, 246-251. doi:10.1016/j.bbrc.2010.04.073

Ammons, M. C. (2010). Anti-biofilm strategies and the need for innovations in wound care. Recent Pat. Antiinfect. Drug. Discov. 5, 10-17. doi:10.2174/157489110790112581

Ammons, M. C., Ward, L. S., Dowd, S., and James, G. A. (2011). Combined treatment of Pseudomonas aeruginosa biofilm with lactoferrin and xylitol inhibits the ability of bacteria to respond to damage resulting from lactoferrin iron chelation. Int. J. Antimicrob. Agents 37, 316-323. doi:10.1016/j.ijantimicag.2010.12. 019

Ammons, M. C., Ward, L. S., Fisher, S. T., Wolcott, R. D., and James, G. A. (2009). In vitro susceptibility of established biofilms composed of a clinical wound isolate of Pseudomonas aeruginosa treated with lactoferrin and xylitol. Int. J. Antimicrob. Agents 33, 230-236. doi: 10.1016/j.ijantimicag.2008.08.013

Bals, R. (2000). Epithelial antimicrobial peptides in host defense against infection. Respir. Res. 1, 141-150. doi:10.1186/rr25

Baranska-Rybak, W., Sonesson, A., Nowicki, R., and Schmidtchen,

of D-LL-37 to inhibit biofilm formation of S. aureus and P. aeruginosa, two common pathogens found in chronic infected wounds (Dean et al., 2011a,b). D-LL-37 represents a potential therapeutic candidate by being a protease-resistant peptide that is effective in inhibiting biofilm formation, increasing the rate of twitching motility, and possesses potentially wound-healing properties toward the host, illustrating its potential to be developed as topical treatments against biofilm-forming bacteria in skin wounds. The concentration-dependent effects of LL-37 ranges from antibiofilm and an ability to block neutrophil apoptosis at low $\mathrm{nM}$ levels, to antimicrobial and chemotactic effects at $0.1 \sim 10 \mu \mathrm{M}$ levels, to cytotoxic effects at levels above $10 \mu \mathrm{M}$. Thus, a challenge to the development of AMPs for the treatment of chronic wounds may lie in defining the optimal efficacious concentrations of the peptide within the wound environment. The design of new peptides with a larger therapeutic index between wound-healing properties and eukaryote cytotoxicity is warranted, and indeed this is one direction that the field is going. Other hurdles to market that remain for AMP therapeutics include cost-of-goods and the design of AMPs with pharmacokinetic properties that maintain optimal drug exposure levels at the target site of infection. To that end, since AMP therapeutics may be effective as an add-on to current therapy, they should also be evaluated for their effectiveness in the presence of standard antibiotics (Brandenburg et al., 2012). It is clear that the data to date for LL-37 as a potential treatment for infected wounds is encouraging. The use of multiple concurrent strategies to treat these wounds is likely to be most effective, combining physical debridement, systemic antibiotics, and topical treatments such as peptides that are able to reduce biofilm.

\section{ACKNOWLEDGMENTS}

The authors (Allen J. Duplantier and Monique L. van Hoek) were supported by HDTRA1-12-C-0039 Translational Peptide Research for Personnel Protection. The authors acknowledge Joel Schnur and Barney Bishop as co-investigators on the Grant, and for helpful general discussions.

A. (2006). Glycosaminoglycans inhibit the antibacterial activity of LL-37 in biological fluids. J. Antimicrob. Chemother. 57, 260-265. doi:10.1093/jac/dki460

Bowdish, D. M., Davidson, D. J., Speert, D. P., and Hancock, R. E. (2004). The human cationic peptide LL-37 induces activation of the extracellular signal-regulated kinase and p38 kinase pathways in primary human monocytes. J. Immunol. 172, 3758-3765.

Braff, M. H., Zaiou, M., Fierer, J., Nizet, V., and Gallo, R. L. (2005). Keratinocyte production of cathelicidin provides direct activity against bacterial skin pathogens. Infect. Immun. 73, 6771-6781. doi:10.1128/IAI.73.10.67716781.2005
Brandenburg, L.-O., Merres, J., Albrecht, L.-J., Varoga, D., and Pufe, T. (2012). Antimicrobial peptides: multifunctional drugs for different applications. Polymers 4, 539-560. doi:10.3390/polym4010539

Brogden, K. A. (2005). Antimicrobial peptides: pore formers or metabolic inhibitors in bacteria? Nat. Rev. Microbiol. 3, 238-250. doi:10.1038/nrmicro1098

Brown, K. V., Murray, C. K., and Clasper, J. C. (2010). Infectious complications of combatrelated mangled extremity injuries in the British military. J. Trauma 69(Suppl. 1), S109-S115. doi:10.1097/TA.0b013e3181e4b33d

Burton, M. F., and Steel, P. G. (2009). The chemistry and biology of LL37. Nat. Prod. Rep. 26, 1572-1584. doi:10.1039/b912533g 
Carretero, M., Escámez, M. J., García, M., Duarte, B., Holguín, A., Retamosa, L., et al. (2008). In vitro and in vivo wound healing-promoting activities of human cathelicidin LL37. J. Invest. Dermatol. 128, 223-236. doi:10.1038/sj.jid.5701043

Chalekson, C. P., Neumeister, M. W., and Jaynes, J. (2002). Improvement in burn wound infection and survival with antimicrobial peptide D2A21 (Demegel). Plast. Reconstr. Surg. 109, 1338-1343. doi:10.1097/00006534200204010-00020

Chamorro, C. I., Weber, G., Grönberg, A., Pivarcsi, A., and Ståhle, M. (2009). The human antimicrobial peptide LL-37 suppresses apoptosis in keratinocytes. J. Invest. Dermatol. 129, 937-944. doi:10.1038/jid.2008.321

Chang, T. W., Lin, Y. M., Wang, C. F., and Liao, Y. D. (2012). Outer membrane lipoprotein Lpp is Gram-negative bacterial cell surface receptor for cationic antimicrobial peptides. J. Biol. Chem. 287, 418-428. doi:10.1074/jbc.M111.290 361

Ciornei, C. D., Sigurdardóttir, T., Schmidtchen, A., and Bodelsson, M. (2005). Antimicrobial and chemoattractant activity, lipopolysaccharide neutralization, cytotoxicity, and inhibition by serum of analogs of human cathelicidin LL-37. Antimicrob. Agents Chemother. 49, 2845-2850. doi:10.1128/AAC.49.7.28452850.2005

Coenye, T. (2010). Response of sessile cells to stress: from changes in gene expression to phenotypic adaptation. FEMS Immunol. Med. Microbiol. 59, 239-252. doi:10.1111/j.1574695X.2010.00682.x

Costerton, J. W., Lewandowski, Z., Caldwell, D. E., Korber, D. R., and Lappin-Scott, H. M. (1995). Microbial biofilms. Annu. Rev. Microbiol. 49, 711-745. doi:10.1146/annurev.mi.49.100195. 003431

Davies, D. G., and Marques, C. N. (2009). A fatty acid messenger is responsible for inducing dispersion in microbial biofilms. J. Bacteriol. 191, 1393-1403. doi:10.1128/JB.01214-08

de Latour, F. A., Amer, L. S., Papanstasiou, E. A., Bishop, B. M., and van Hoek, M. L. (2010). Antimicrobial activity of the Naja atra cathelicidin and related small peptides. Biochem. Biophys. Res. Commun. 396, 825-830. doi:10.1016/j.bbrc.2010.04.158
Dean, S. N., Bishop, B. M., and van Hoek, M. L. (2011a). Susceptibility of Pseudomonas aeruginosa biofilm to alphahelical peptides: D-enantiomer of LL-37. Front. Microbiol. 2:128. doi:10.3389/fmicb.2011.00128

Dean, S. N., Bishop, B. M., and van Hoek, M. L. (2011b). Natural and synthetic cathelicidin peptides with anti-microbial and antibiofilm activity against Staphylococcus aureus. BMC Microbiol. 11:114. doi:10.1186/1471-2180-11-114

Development Program LL-37. (2012). Available at: http://www.pergamum. com/ll-37/development/

Dowd, S. E., Sun, Y., Secor, P. R., Rhoads, D. D., Wolcott, B. M., James, G. A., et al. (2008). Survey of bacterial diversity in chronic wounds using pyrosequencing, DGGE, and full ribosome shotgun sequencing. BMC Microbiol. 8:43. doi:10.1186/1471-2180-843

Dowd, S. E., Sun, Y., Smith, E., Kennedy, J. P., Jones, C. E., and Wolcott, R. (2009). Effects of biofilm treatments on the multi-species Lubbock chronic wound biofilm model. J. Wound Care 18, 508.

Durr, U. H., Sudheendra, U. S., and Ramamoorthy, A. (2006). LL-37, the only human member of the cathelicidin family of antimicrobial peptides. Biochim. Biophys. Acta 1758, 1408-1425. doi:10.1016/j.bbamem.2006.03.030

Edwards, R., and Harding, K. G. (2004). Bacteria and wound healing. Curr. Opin. Infect. Dis. 17, 91-96. doi:10.1097/00001432-20040400000004

Eissa, A., Amodeo, V., Smith, C. R., and Diamandis, E. P. (2011). Kallikreinrelated peptidase-8 (KLK8) is an active serine protease in human epidermis and sweat and is involved in a skin barrier proteolytic cascade. J. Biol. Chem. 286, 687-706. doi:10.1074/jbc.M110.125310

Elssner, A., Duncan, M., Gavrilin, M., and Wewers, M. D. (2004). A novel $\mathrm{P} 2 \times 7$ receptor activator, the human cathelicidin-derived peptide LL37, induces IL-1 beta processing and release. J. Immunol. 172, 4987-4994.

Fisher, T. K., Wolcott, R., Wolk, D. M., Bharara, M., Kimbriel, H. R., and Armstrong, D. G. (2010). Diabetic foot infections: a need for innovative assessments. Int. J. Low. Extrem. Wounds 9, 31-36. doi:10.1177/1534734610363459

Flemming, K., Klingenberg, C., Cavanagh, J. P., Sletteng, M., Stensen, W., Svendsen, J. S., et al. (2009). High in vitro antimicrobial activity of synthetic antimicrobial peptidomimetics against staphylococcal biofilms. J. Antimicrob. Chemother. 63, 136-145. doi:10.1093/jac/dkn464

Girnita, A., Zheng, H., Grönberg, A., Girnita, L., and Ståhle, M. (2012). Identification of the cathelicidin peptide LL-37 as agonist for the type I insulin-like growth factor receptor. Oncogene 31, 352-365. doi:10.1038/onc.2011.239

Gronberg, A., Zettergren, L., and Agren, M. S. (2011). Stability of the cathelicidin peptide LL-37 in a non-healing wound environment. Acta Derm. Venereol. 91, 511-515. doi:10.2340/00015555-1102

Heilborn, J. D., Nilsson, M. F., Kratz, G., Weber, G., Sørensen, O., Borregaard, N., et al. (2003). The cathelicidin anti-microbial peptide LL-37 is involved in reepithelialization of human skin wounds and is lacking in chronic ulcer epithelium. J. Invest. Dermatol. 120, 379-389. doi:10.1046/j.15231747.2003.12069.x

Hirsch, T., Spielmann, M., Zuhaili, B. Fossum, M., Metzig, M., Koehler, T., et al. (2009). Human betadefensin-3 promotes wound healing in infected diabetic wounds. J. Gene Med. 11, 220-228. doi:10.1002/jgm.1287

Hoyer, J., Schatzschneider, U., SchulzSiegmund, M., and Neundorf, I. (2012). Dimerization of a cell-penetrating peptide leads to enhanced cellular uptake and drug delivery. Beilstein J. Org. Chem. 8, 1788-1797. doi:10.3762/bjoc.8.204

Hurdle, J. G., O'Neill, A. J., Chopra I., and Lee, R. E. (2011). Targeting bacterial membrane function: an underexploited mechanism for treating persistent infections. Nat. Rev. Microbiol. 9, 62-75. doi:10.1038/nrmicro2474

Isaksson, J., Brandsdal, B. O., Engqvist, M., Flaten, G. E., Svendsen, J. S., and Stensen, W. (2011). A synthetic antimicrobial peptidomimetic (LTX 109): stereochemical impact on membrane disruption. $J$. Med. Chem. 54, 5786-5795. doi:10.1021/jm200450h

Jacobsen, A. S., and Jenssen, H. (2012). Human cathelicidin LL-37 prevents bacterial biofilm formation. Future Med. Chem. 4, 1587-1599. doi:10.4155/fmc. 12.97

James, G. A., Swogger, E., Wolcott, R., Pulcini, E. D., Secor, P., Sestrich, J., et al. (2008). Biofilms in chronic wounds. Wound Repair Regen. 16, 37-44. doi:10.1111/j.1524475X.2007.00321.x
Jiang, Z., Higgins, M. P., Whitehurst, J., Kisich, K. O., Voskuil, M. I., and Hodges, R. S. (2011) Anti-tuberculosis activity of alphahelical antimicrobial peptides: de novo designed $\mathrm{L}-$ and $\mathrm{D}$ enantiomers versus L- and D-LL-37. Protein Pept. Lett. 18, 241-252. doi:10.2174/092986611794578288

Johansson, J., Gudmundsson, G. H., Rottenberg, M. E., Berndt, K. D., and Agerberth, B. (1998). Conformation-dependent antibacterial activity of the naturally occurring human peptide LL-37. J. Biol. Chem. 273, 3718-3724. doi:10.1074/jbc.273.6.3718

Johnson, E. N., Burns, T. C., Hayda, R. A., Hospenthal, D. R., and Murray, C. K. (2007). Infectious complications of open type III tibial fractures among combat casualties. Clin. Infect. Dis. 45, 409-415. doi:10.1086/520029

Kai-Larsen, Y., and Agerberth, B. (2008). The role of the multifunctional peptide LL-37 in host defense. Front. Biosci. 13, 3760-3767. doi:10.2741/2964

Kamiya, H., Ehara, T., and Matsumoto, T. (2012). Inhibitory effects of lactoferrin on biofilm formation in clinical isolates of Pseudomonas aeruginosa. J. Infect. Chemother. 18, 47-52. doi:10.1007/s10156-011-0287-1

Kanada, K. N., Nakatsuji, T., and Gallo, R. L. (2012). Doxycycline indirectly inhibits proteolytic activation of tryptic kallikrein-related peptidases and activation of cathelicidin. J. Invest. Dermatol. 132, 1435-1442. doi:10.1038/jid.2012.14

Kanthawong, S., Bolscher, J. G., Veerman, E. C., van Marle, J., de Soet, H. J., Nazmi, K., et al. (2012). Antimicrobial and antibiofilm activity of LL-37 and its truncated variants against Burkholderia pseudomallei. Int. J. Antimicrob. Agents 39, 39-44. doi:10.1016/j.ijantimicag.2011.09.010

Kiran, M. D., Adikesavan, N. V., Cirioni, O., Giacometti, A., Silvestri, C., Scalise, G., et al. (2008). Discovery of a quorum-sensing inhibitor of drugresistant staphylococcal infections by structure-based virtual screening. Mol. Pharmacol. 73, 1578-1586. doi:10.1124/mol.107.044164

Lan, Y., Ye, Y., Kozlowska, J., Lam, J. K., Drake, A. F., and Mason, A. J. (2010). Structural contributions to the intracellular targeting strategies of antimicrobial peptides. Biochim. Biophys. Acta 1798, 1934-1943. doi:10.1016/j.bbamem.2010.07.003

Lippross, S., Klueter, T., Steubesand, N., Oestern, S., Mentlein, R., Hildebrandt, F., et al. (2012). 
Multiple trauma induces serum production of host defence peptides. Injury 43, 137-142. doi:10.1016/j.injury.2011.03.044

Lopez-Leban, F., Kiran, M. D., Wolcott, R., and Balaban, N. (2010). Molecular mechanisms of RIP, an effective inhibitor of chronic infections. Int J. Artif. Organs 33, 582-589.

Madani, F., Lindberg, S., Langel, U., Futaki, S., and Gräslund, A. (2011). Mechanisms of cellular uptake of cell-penetrating peptides. J. Biophys. 2011, 414729. doi:10.1155/2011/414729

Marsh, E. N., Buer, B. C., and Ramamoorthy, A. (2009). Fluorine - a new element in the design of membrane-active peptides. Mol. Biosyst. 5, 1143-1147. doi:10.1039/b909864j

Mendez-Samperio, P. (2010). The human cathelicidin hCAP18/LL37: a multifunctional peptide involved in mycobacterial infections. Peptides 31, 1791-1798. doi:10.1016/j.peptides.2010.06.016

Mikkelsen, H., Sivaneson, M., and Filloux, A. (2011). Key two-component regulatory systems that control biofilm formation in Pseudomonas aeruginosa. Environ. Microbiol. 13, 1666-1681. doi:10.1111/j.14622920.2011.02495.x

Monds, R. D., and O'Toole, G. A. (2009). The developmental model of microbial biofilms: ten years of a paradigm up for review. Trends Microbiol. 17, 73-87. doi:10.1016/j.tim.2008.11.001

Mookherjee, N., Brown, K. L., Bowdish, D. M., Doria, S., Falsafi, R., Hokamp, K., et al. (2006). Modulation of the TLR-mediated inflammatory response by the endogenous human host defense peptide LL-37. J. Immunol. 176, 2455-2464.

Morrisey, I., Dallow, J., Siegwart, E., Smith, A., Scott, R., and Korczak, B. (2012). "The activity of PMX-30063 against staphylococci and streptococci," in 22nd European Congress of Clinical Microbiology and Infectious Diseases (ECCMID), London, P1458.

Murray, C. K. (2008a). Infectious disease complications of combat-related injuries. Crit. Care Med. 36(Suppl. 7), S358-S364. doi:10.1097/CCM.0b013e31817e2ffc

Murray, C. K. (2008b). Epidemiology of infections associated with combat-related injuries in Iraq and Afghanistan. $J$. Trauma 64(Suppl. 3), S232-S238. doi:10.1097/TA.0b013e318163c3f5

Nagaoka, I., Hirota, S., Niyonsaba, F., Hirata, M., Adachi, Y., Tamura, H., et al. (2001). Cathelicidin family of antibacterial peptides CAP18 and CAP11 inhibit the expression of TNF-alpha by blocking the binding of LPS to CD14(+) cells. J. Immunol. 167, 3329-3338.

Nagaoka, I., Tamura, H., and Hirata, M. (2006). An antimicrobial cathelicidin peptide, human CAP18/LL37, suppresses neutrophil apoptosis via the activation of formylpeptide receptor-like 1 and $\mathrm{P} 2 \times 7$. J. Immunol. 176, 3044-3052.

Nell, M. J., Tjabringa, G. S., Wafelman, A. R., Verrijk, R., Hiemstra, P. S., Drijfhout, J. W., et al. (2006). Development of novel LL-37 derived antimicrobial peptides with LPS and LTA neutralizing and antimicrobial activities for therapeutic application. Peptides 27, 649-660. doi:10.1016/j.peptides.2005.09.016

Nijnik, A., and Hancock, R. E. (2009). The roles of cathelicidin LL-37 in immune defences and novel clinical applications. Curr. Opin. Hematol. 16, 41-47. doi:10.1097/MOH.0b013e32831ac517

Nijnik, A., Pistolic, J., Filewod, N. C., and Hancock, R. E. (2012). Signaling pathways mediating chemokine induction in keratinocytes by cathelicidin LL-37 and flagellin. J. Innate Immun. 4, 377-386. doi:10.1159/000335901

Oudhoff, M. J., Blaauboer, M. E., Nazmi, K., Scheres, N., Bolscher, J. G., and Veerman, E. C. (2010). The role of salivary histatin and the human cathelicidin LL-37 in wound healing and innate immunity. Biol. Chem. 391, 541-548. doi:10.1515/BC.2010.057

Overhage, J., Campisano, A., Bains, M., Torfs, E. C., Rehm, B. H., and Hancock, R. E. (2008). Human host defense peptide LL-37 prevents bacterial biofilm formation. Infect. Immun. 76, 4176-4182. doi:10.1128/IAI.00318-08

Park, H. J., Cho, D. H., Kim, H. J., Lee, J. Y., Cho, B. K., Bang, S. I., et al. (2009). Collagen synthesis is suppressed in dermal fibroblasts by the human antimicrobial peptide LL-37. J. Invest. Dermatol. 129, 843-850. doi:10.1038/jid.2008.320

Petrova, O. E., and Sauer, K. (2012). Sticky situations: key components that control bacterial surface attachment. J. Bacteriol. 194, 2413-2425. doi:10.1128/JB.00003-12

Porcelli, F., Verardi, R., Shi, L., HenzlerWildman, K. A., Ramamoorthy, A., and Veglia, G. (2008). NMR structure of the cathelicidin-derived human antimicrobial peptide LL-37 in dodecylphosphocholine micelles.
Biochemistry $\quad 47, \quad 5565-5572$. doi:10.1021/bi702036s

Reinholz, M., Ruzicka, T., and Schauber, J. (2012). Cathelicidin LL-37: an antimicrobial peptide with a role in inflammatory skin disease. Ann. Dermatol. 24, 126-135. doi:10.5021/ad.2012.24.2.126

Ressner, R. A., Murray, C. K., Griffith, M. E., Rasnake, M. S., Hospenthal, D. R., Wolf, S. E., et al. (2008). Outcomes of bacteremia in burn patients involved in combat operations overseas. J. Am. Coll. Surg. 206, 439-444. doi:10.1016/j.jamcollsurg.2007.09. 017

Rivas-Santiago, B., Trujillo, V., Montoya, A., Gonzalez-Curiel, I., CastañedaDelgado, J., Cardenas, A., et al. (2012). Expression of antimicrobial peptides in diabetic foot ulcer. J. Dermatol. Sci. 65, 19-26. doi:10.1016/j.jdermsci.2011.09.013

Ross, J. E., Jones, R. N., Rhomberg, P. R., and Fritsche, T. R. (2007). "In vitro activity of omiganan pentahydrochloride against $>1,600$ clinical trial isolates," in 45th Infectious Diseases Society of America Annual Meeting, San Diego, CA, Abstr. 433.

Saiman, L., Tabibi, S., Starner, T. D., San Gabriel, P., Winokur, P. L., Jia, H. P., et al. (2001). Cathelicidin peptides inhibit multiply antibioticresistant pathogens from patients with cystic fibrosis. Antimicrob. Agents Chemother. 45, 2838-2844. doi:10.1128/AAC.45.10.28382844.2001

Schauber, J., Oda, Y., Büchau, A. S., Yun, Q. C., Steinmeyer, A., Zügel, U., et al. (2008). Histone acetylation in keratinocytes enables control of the expression of cathelicidin and CD14 by 1,25-dihydroxyvitamin D3. J. Invest. Dermatol. 128, 816-824. doi:10.1038/sj.jid.5701102

Schiemann, F., Brandt, E., Gross, R., Lindner, B., Mittelstädt, J., Sommerhoff, C. P., et al. (2009). The cathelicidin LL-37 activates human mast cells and is degraded by mast cell tryptase: counter-regulation by CXCL4. J. Immunol. 183, 2223-2231. doi:10.4049/jimmunol.0803587

Schierle, C. F., De la Garza, M., Mustoe, T. A., and Galiano, R. D. (2009). Staphylococcal biofilms impair wound healing by delaying reepithelialization in a murine cutaneous wound model. Wound Repair Regen. 17, 354-359. doi:10.1111/j.1524475X.2009.00489.X

Schittek, B., Paulmann, M., Senyürek, I., and Steffen, H. (2008). The role of antimicrobial peptides in human skin and in skin infectious diseases. Infect. Disord. Drug Targets 8, 135-143. doi:10.2174/1871526510808030135

Schmidtchen, A., Frick, I. M., Andersson, E., Tapper, H., and Björck, L. (2002). Proteinases of common pathogenic bacteria degrade and inactivate the antibacterial peptide LL-37. Mol. Microbiol 46, 157-168. doi:10.1046/j.13652958.2002.03146.x

Scott, M. G., Vreugdenhil, A. C., Buurman, W. A., Hancock, R. E., and Gold, M. R. (2000). Cutting edge: cationic antimicrobial peptides block the binding of lipopolysaccharide (LPS) to LPS binding protein. J. Immunol. 164, 549-553.

Shaykhiev, R., Beisswenger, C., Kändler K., Senske, J., Püchner, A., Damm T., et al. (2005). Human endogenous antibiotic LL-37 stimulates airway epithelial cell proliferation and wound closure. Am. J. Physiol. Lung Cell Mol. Physiol. 289, L842-L848. doi:10.1152/ajplung.00286.2004

Shu, W., Liu, J., Ji, H., and Lu, M. (2000). Core structure of the outer membrane lipoprotein from Escherichia coli at 1.9 A resolution. J. Mol. Biol. 299, 1101-1112. doi:10.1006/jmbi.2000.3776

Sochacki, K. A., Barns, K. J., Bucki, R., and Weisshaar, J. C. (2011). Realtime attack on single Escherichia coli cells by the human antimicrobial peptide LL-37. Proc. Natl. Acad. Sci. U.S.A. 108, E77-E81. doi:10.1073/pnas.1101130108

Sørensen, O., Cowland, J. B., Askaa, J., and Borregaard, N. (1997). An ELISA for hCAP-18, the cathelicidin present in human neutrophils and plasma. J. Immunol. Methods 206, 53-59. doi:10.1016/S00221759(97)00084-7

Sørensen, O. E., Cowland, J. B., Theilgaard-Mönch, K., Liu, L., Ganz, T., and Borregaard, N. (2003). Wound healing and expression of antimicrobial peptides/polypeptides in human keratinocytes, a consequence of common growth factors. J. Immunol. 170, 5583-5589.

Sørensen, O. E., Follin, P., Johnsen, A. H., Calafat, J., Tjabringa, G. S., Hiemstra, P. S., et al. (2001). Human cathelicidin, hCAP- 18 , is processed to the antimicrobial peptide LL37 by extracellular cleavage with proteinase 3. Blood 97, 3951-3959. doi:10.1182/blood.V97.12.3951

Subramanian, H., Gupta, K., Guo, Q., Price, R., and Ali, H. (2011). Mas-related gene $\mathrm{X} 2(\mathrm{MrgX} 2)$ is a novel $G$ protein-coupled receptor for the antimicrobial peptide 
LL-37 in human mast cells: resistance to receptor phosphorylation, desensitization, and internalization. J. Biol. Chem. 286, 44739-44749. doi:10.1074/jbc.M111.277152

Sun, Y., Dowd, S. E., Smith, E., Rhoads, D. D., and Wolcott, R. D. (2008). In vitro multispecies Lubbock chronic wound biofilm model. Wound Repair Regen. 16, 805-813. doi:10.1111/j.1524475X.2008.00434.x

Takeshima, K., Chikushi, A., Lee, K. K., Yonehara, S., and Matsuzaki, K. (2003). Translocation of analogues of the antimicrobial peptides magainin and buforin across human cell membranes. J. Biol. Chem. 278, 1310-1315. doi:10.1074/jbc.M208762200

Thoma-Uszynski, S., Stenger, S., Takeuchi, O., Ochoa, M. T., Engele, M., Sieling, P. A., et al. (2001). Induction of direct antimicrobial activity through mammalian toll-like receptors. Science 291, 1544-1547. doi:10.1126/ science.291.5508.1544

Tokumaru, S., Sayama, K., Shirakata, Y., Komatsuzawa, H., Ouhara, K., Hanakawa, Y., et al. (2005). Induction of keratinocyte migration via transactivation of the epidermal growth factor receptor by the antimicrobial peptide LL-37. J. Immunol. 175, 4662-4668.

Tomasinsig, L., Pizzirani, C., Skerlavaj, B., Pellegatti, P., Gulinelli, S., Tossi, A., et al. (2008). The human cathelicidin LL-37 modulates the activities of the $\mathrm{P} 2 \times 7$ receptor in a structure-dependent manner. J. Biol. Chem. 283, 30471-30481. doi:10.1074/jbc.M802185200

Vandamme, D., Landuyt, B., Luyten, W., and Schoofs, L. (2012). A comprehensive summary of LL-37, the factotum human cathelicidin peptide.
Cell. Immunol. 280, 22-35. doi:10. 1016/j.cellimm.2012.11.009

Wang, G. (2008). Structures of human host defense cathelicidin LL-37 and its smallest antimicrobial peptide KR-12 in lipid micelles. J. Biol. Chem. 283, 32637-32643. doi:10.1074/jbc.M805533200

Wang, G., Li, X., and Wang, Z. (2009). APD2: the updated antimicrobial peptide database and its application in peptide design. Nucleic Acids Res. 37, D933-D937. doi:10.1093/nar/gkn823

Wewers, M. D., and Sarkar, A. (2009). P2X(7) receptor and macrophage function. Purinergic Signal. 5, 189-195. doi:10.1007/s11302-009-9131-9

Wolcott, R. D., Cox, S. B., and Dowd, S. E. (2010a). Healing and healing rates of chronic wounds in the age of molecular pathogen diagnostics. J. Wound Care 19, 272-278.

Wolcott, R. D., Rhoads, D. D., Bennett, M. E., Wolcott, B. M., Gogokhia, L., Costerton, J. W., et al. (2010b). Chronic wounds and the medical biofilm paradigm. J. Wound Care 19, 45-46.

Wolcott, R. D., Rumbaugh, K. P., James, G., Schultz, G., Phillips, P., Yang, Q., et al. (2010c). Biofilm maturity studies indicate sharp debridement opens a time-dependent therapeutic window. J. Wound Care 19, 320-328.

Wolcott, R. D., Kennedy, J. P., and Dowd, S. E. (2009). Regular debridement is the main tool for maintaining a healthy wound bed in most chronic wounds. J. Wound Care 18, 54-56.

Wolcott, R. D., Lopez-Leban, F., and Kiran, M. D. (2011). "Wound Healing by an Anti-Staphylococcal Biofilm Approach," Biofilm Highlights, Chap. 7, eds H.-C. Flemming, J. Wingender, and U. Szewzyk (Berlin: Springer-Verlag), 141-161.
Wolcott, R. D., and Rhoads, D. D. (2008). A study of biofilm-based wound management in subjects with critical limb ischaemia. J. Wound Care 17, 145-148.

Wolcott, R. D., Rhoads, D. D., and Dowd, S. E. (2008). Biofilms and chronic wound inflammation. J. Wound Care 17, 333-341.

Yamasaki, K., Schauber, J., Coda, A., Lin, H., Dorschner, R. A., Schechter, N. M., et al. (2006). Kallikreinmediated proteolysis regulates the antimicrobial effects of cathelicidins in skin. FASEB J. 20, 2068-2080. doi:10.1096/fj.06-6075com

Yang, D., Chen, Q., Schmidt, A. P., Anderson, G. M., Wang, J. M., Wooters, J., et al. (2000). LL37 , the neutrophil granule- and epithelial cell-derived cathelicidin, utilizes formyl peptide receptorlike 1 (FPRL1) as a receptor to chemoattract human peripheral blood neutrophils, monocytes, and T cells. J. Exp. Med. 192, 1069-1074. doi:10.1084/jem.192.7.1069

Yeaman, M. R., and Yount, N. Y. (2003). Mechanisms of antimicrobial peptide action and resistance. Pharmacol. Rev. 55, 27-55. doi:10.1124/pr.55.1.2

Yoshioka, M., Fukuishi, N., Kubo, Y. Yamanobe, H., Ohsaki, K., Kawasoe, Y., et al. (2008). Human cathelicidin CAP18/LL-37 changes mast cell function toward innate immunity. Biol. Pharm. Bull. 31, 212-216. doi:10.1248/bpb.31.212

Zaiou, M., Nizet, V., and Gallo, R. L. (2003). Antimicrobial and protease inhibitory functions of the human cathelicidin (hCAP18/LL37) prosequence. J. Invest. Dermatol. 120, 810-816. doi:10.1046/j.15231747.2003.12132.x

Zasloff, M. (2002). Antimicrobial peptides of multicellular organisms. Nature 415, 389-395. doi:10.1038/415389a

Zhang, X., Oglecka, K., Sandgren, S., Belting, M., and Esbjörner, E. K. (2010). Dual functions of the human antimicrobial peptide LL37-target membrane perturbation and host cell cargo delivery. Biochim. Biophys. Acta 1798, 2201-2208. doi:10.1016/j.bbamem.2009.12.011

Zhang, Z., Cherryholmes, G., Chang, F., Rose, D. M., Schraufstatter, I. and Shively, J. E. (2009). Evidence that cathelicidin peptide LL37 may act as a functional ligand for CXCR2 on human neutrophils. Eur. J. Immunol. 39, 3181-3194. doi:10.1002/eji.200939496

Conflict of Interest Statement: The authors declare that the research was conducted in the absence of any commercial or financial relationships that could be construed as a potential conflict of interest.

Received: 06 February 2013; paper pending published: 26 March 2013; accepted: 28 May 2013; published online: 03 July 2013.

Citation: Duplantier AJ and van Hoek $M L$ (2013) The human cathelicidin antimicrobial peptide $L L-37$ as a potential treatment for polymicrobial infected wounds. Front. Immunol. 4:143. doi: 10.3389/fimmu.2013.00143

This article was submitted to Frontiers in Molecular Innate Immunity, a specialty of Frontiers in Immunology.

Copyright (c) 2013 Duplantier and van Hoek. This is an open-access article distributed under the terms of the Creative Commons Attribution License, which permits use, distribution and reproduction in other forums, provided the original authors and source are credited and subject to any copyright notices concerning any third-party graphics etc. 